Note

\title{
Research note: Exceptional absolute pitch perception for spoken words in an able adult with autism
}

\author{
Pamela Heaton $^{\mathrm{a}, *}$, Robert E. Davis ${ }^{\mathrm{a}}$, Francesca G.E. Happé ${ }^{\mathrm{b}}$ \\ ${ }^{a}$ Department of Psychology, Goldsmiths College, University of London, New Cross, London SE14 6NW, United Kingdom \\ ${ }^{\mathrm{b}}$ SGDP Research Centre, Institute of Psychiatry, King's College, De Crespigny Park, London SE5 8AF, United Kingdom
}

Received 5 November 2007; received in revised form 30 January 2008; accepted 1 February 2008

Available online 9 February 2008

\begin{abstract}
Autism is a neurodevelopmental disorder, characterised by deficits in socialisation and communication, with repetitive and stereotyped behaviours [American Psychiatric Association (1994). Diagnostic and statistical manual for mental disorders (4th ed.). Washington, DC: APA]. Whilst intellectual and language impairment is observed in a significant proportion of diagnosed individuals [Gillberg, C., \& Coleman, M. (2000). The biology of the autistic syndromes (3rd ed.). London: Mac Keith Press; Klinger, L., Dawson, G., \& Renner, P. (2002). Autistic disorder. In E. Masn, \& R. Barkley (Eds.), Child pyschopathology (2nd ed., pp. 409-454). New York: Guildford Press], the disorder is also strongly associated with the presence of highly developed, idiosyncratic, or savant skills [Heaton, P., \& Wallace, G. (2004) Annotation: The savant syndrome. Journal of Child Psychology and Psychiatry, 45 (5), 899-911]. We tested identification of fundamental pitch frequencies in complex tones, sine tones and words in AC, an intellectually able man with autism and absolute pitch (AP) and a group of healthy controls with self-reported AP. The analysis showed that AC's naming of speech pitch was highly superior in comparison to controls. The results suggest that explicit access to perceptual information in speech is retained to a significantly higher degree in autism.
\end{abstract}

(C) 2008 Elsevier Ltd. All rights reserved.

Keywords: Autism; Absolute pitch

\section{Introduction}

The nature and genesis of absolute pitch (AP), or the rare ability to name isolated decontextualised musical tones has been the subject of much recent scientific debate. Several researchers have suggested that AP is a normally distributed complex trait with a strong genetic component (Baharloo, Service, Risch, Gitschier, \& Freimer, 2000; Gregersen, Kowalsky, Kohn, \& Marvin, 2000) that relies on early musical exposure for its expression. However, in line with fMRI studies showing that AP is associated with structural differences in the brain (Schlaug, Jaencke, Huang, \& Steinmetz, 1995; Zatorre, 2003), a recent survey of more than 2000 individuals with self-reported AP observed a bi-modal distribution for this trait (Athos et al., 2007). Whilst this latter finding suggests that AP may be under the influence of one or a limited number of genes, it should

\footnotetext{
* Corresponding author.

E-mail address: p.heaton@gold.ac.uk (P. Heaton).
}

be noted that AP was not verified independently and whilst the sample size was large, self-selection biases cannot be ruled out.

Less well understood is the question of why AP might be more frequently represented in individuals with atypical neurodevelopment. Whilst AP appears to be a universally occuring correlate of musical savantism in autism (Mottron, Peretz, Belleville, \& Touleau, 1999; Young \& Nettlebeck, 1995) research has identified both exceptional memory for verbally labelled musical tones (Heaton, 2003) and unusually fine-grained discrimination of musical tones (Bonnel et al., 2003; Heaton, 2005) in musically naïve children and adults with autism. More recent findings also suggest that enhanced discrimination of pitch information in autism, identified in studies using musical stimuli, generalises to the language domain. For example, in one study where autistic children and age and intelligence matched typical controls were required to pair speech samples with graphic representations of their different pitch contours (Järvinen-Pasley, Pasley, \& Heaton, 2008) highly superior performance was observed in the autism group. Findings by Zatorre and Belin (2001) have shown 
that the left auditory cortex is specialised for rapidly changing broad-band stimuli, including speech, whilst right auditory cortex is specialised for narrow-band stimuli such as tonal patterns. Findings showing increased sensitivity to speech pitch in autism may therefore represent a behavioural correlate of atypical hemisphere activation in response to speech and non-speech auditory stimuli in autism (e.g. Čeponienė et al., 2003; Gervais et al., 2004).

In healthy populations, enhanced sensitivity to changes in fundamental frequency in speech, most commonly reflects language experience or direct training, as observed, for example, in speakers of tone languages (Bent, Bradlow, \& Wright, 2006) and musicians (Wong, Skoe, Russo, Dees, \& Kraus, 2007). Musicians with and without AP may not differ in sensitivity to changes in speech pitch as AP specifically relates to the ability to name tones presented without musical context. However, musicians with AP may be better able to name fundamental frequencies in speech when these encompass the same frequency ranges as musical tones. As verbal labelling of speech pitch has been reported in our subject, $\mathrm{AC}$ anecdotally, we compared his speech pitch naming with that of a group of healthy professional and amateur musicians with AP.

\section{Methods}

\subsection{Subjects}

AC was 35 years old at the time of testing. He was formally diagnosed with autism in early childhood and his early language development was typical for a child with this diagnosis: he began to produce single words and to echo sentences and phrases from the age of 3 years, and produced his first semantically meaningful sentences at around 6 years. AC is a native French speaker, but spent extended periods in the US and the UK and he was exposed to English from the age of $21 / 2$ years. In our study he obtained scores within the normal range on a standardised English vocabulary test (Peabody Picture Vocabulary Test; Dunn, 1965) and on a non-verbal intelligence test (Raven's Progressive Matrices; Raven, Raven, \& Court, 1998)

In addition to his native French, AC speaks English, Italian, Spanish and Dutch and is currently studying Danish, Japanese, German and Chinese. Whilst polyglot savant skills have been previously reported in one individual with autism (Smith \& Tsimpli, 1995), impoverished language is more commonly characteristic of this disorder, and AC is highly atypical in this respect.

AC's father, who does not possess AP is an amateur improvising pianist and $\mathrm{AC}$ was exposed to music in the home. He showed evidence of AP by 3 years, and was reported to remember the keys of music he heard. AC's unusually fine pitch memory appears to have influenced his perception of many aspects of his auditory world. For example, he became very distressed when travelling on the Paris Metro, because the pitch frequency of the opening-door signal was different to the one used on the London Underground. AC's father reports how once he had acquired note names, (e.g. C, C\#, D), all sounds were immediately associated with these. So once he had acquired language he began to question his parents about their tendency to produce words at varying pitch levels, for example by asking, "why when you call "dinner is ready" (do) you make a D and mom makes an A?".

In the study AC's pitch naming skills were compared with that of a group (see Table 1) of nine healthy adults with self-reported AP.

\subsection{Procedure}

The stimuli used were 100 complex (piano) tones and 52 sine tones (spanning four octaves $\mathrm{C} 2-\mathrm{C} 6$ ). Complex tones consist of a fundamental and a number of harmonics that provide more contextual information about the pitch of the fundamental. Sine tones do not have a harmonic component and are there-

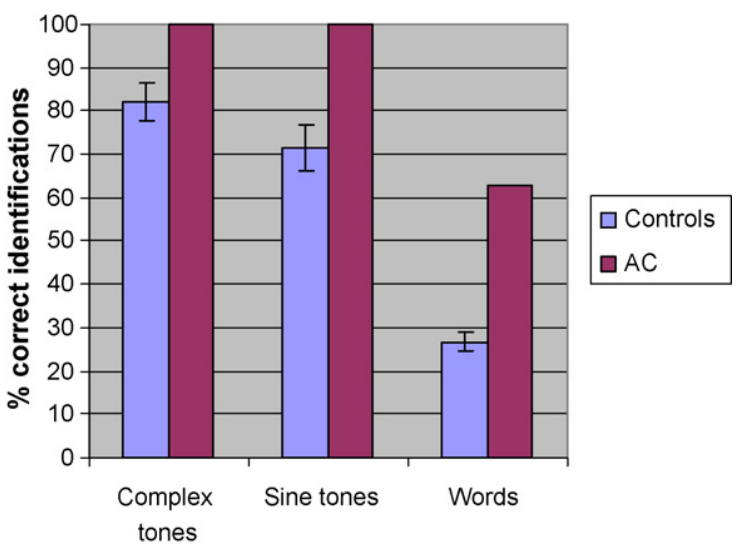

Fig. 1. Percentage of correct pitch identifications across experimental conditions with error bars representing standard error of the mean.

fore more difficult to identify (Athos et al., 2007; Miyazaki, 1989). As the aim of the experiment was to test identification of pitch in naturalistic speech, real, rather than synthesised speech was used. Multiple Versions of 40 highfrequency single syllable French and English words were read and recorded by a bilingual (French/English) speaker. These were processed using Melodyn cre 8 (Neubäcker \& Gehle, 2003), a software package that analyses and identifies the fundamental frequencies of sounds recorded onto audio files. Pitch in speech stimuli does not map onto musical pitch categories (e.g. C, C\#, D, D\#, etc.) but crosses musical pitch category boundaries and includes multiple tones. From the group of recorded words, the 40 (20 in each language) with the highest proportion of pitches with identifiable chroma were selected and recorded onto CD digital audiotapes. The total number of potentially identifiable tones for each stimulus was identified using Melodyne, and participants were scored on the proportion of these they named.

\section{Results}

The total percentage scores for identification are shown in Fig. 1.

An initial analysis carried out on the control group data showed a significant main effect of stimulus type $[F(2,16)=101.88, p<.001]$ with Bonferonni adjusted post hoc $t$-tests revealing superior discrimination of complex tones $($ mean $=82.11$, S.D. $=13.67)$ in comparison to words $($ mean $=26.72$, S.D. $=6.12)$, and superior discrimination of sine tones $($ mean $=71.56$, S.D. $=6.12)$ in comparison to words (both at $p<.001$ ). There was no significant difference between correct identification scores for complex and sine tones. AC's naming of tones was 1.3 standard deviations (complex) and 1.8 standard deviations (sine) higher than controls. However, as he named all of the presented tones correctly, the comparison of his data with that of controls might have been compromised by ceiling effects.

In order to determine whether there was any association between music and speech-pitch naming abilities in controls, we summed the complex and sine tone scores (which did not differ significantly) and correlated this composite score with the word scores. This correlation was highly significant $(r=.897$, $p<.001$ ) indicating that pure (sine) and complex pitch naming skills generalise to an ability to name fundamental tones in words in healthy musicians with AP. However, the most striking find- 
Table 1

Control participant characteristics and complex and sine tone identification

\begin{tabular}{|c|c|c|c|c|c|}
\hline Age & $\begin{array}{l}\text { Music lessons } \\
\text { from (years) }\end{array}$ & Current musical status & First language & Second language from (years) & $\begin{array}{l}\text { Correct score complex } \\
\text { and sine tones }(\%)\end{array}$ \\
\hline 25 & 5 & Ph.D. music student & Mandarin & English from 13 & 95 \\
\hline 32 & 5 & Amateur singer & English & French from 12 & 63 \\
\hline 60 & 10 & Amateur singer/pianist & English & French from 11 & 72 \\
\hline 58 & 4 & Professional singer & English & French from 11 & 90 \\
\hline 23 & 5 & No current activity & French & English from 5 & 55 \\
\hline 22 & 9 & Music graduate & English & None & 79 \\
\hline 28 & 4 & Ph.D. music student & Japanese & English from 23 & 88 \\
\hline 21 & 3 & Ph.D. music student & Japanese & English from 14 & 78 \\
\hline 27 & 5 & Graduate music student & Japanese & English from 13 & 74 \\
\hline
\end{tabular}

ing was that AC's correct identification of pitches in words was 5.92 standard deviations higher than that of the control group.

\section{Discussion}

The analysis showed that AC correctly named $100 \%$ of the complex and sine tones presented. However, four of the participants in the control group named more than $90 \%$ of the complex tones correctly and for two of these sine tone accuracy was also around $90 \%$. Whilst this suggests some similarity in skill levels, consideration of different experiential factors distinguishing AC. and healthy controls with AP suggest that the trajectory of such skills may differ. Whilst AC enjoys music and possesses some instrumental skills, this is not a primary pre-occupation and his level of formal musical training has not been extensive. In contrast, three of the high-accuracy controls have studied musical composition and performance at Doctoral level and the fourth is a professional singer with extensive experience of complex contemporary music performance. Whilst AC did not undergo musical training in early childhood, he was exposed to music and when told the names of musical tones, was able to retain these in memory in the same way that genetically predisposed, typical children exposed to early musical training do.

The analysis of the control group data suggests that whilst fundamental tones in speech are very much more difficult to name than complex or sine tones, similar cognitive mechanisms are implicated in both tasks. It was interesting that the one control whose first language was Mandarin (a tonal language) achieved the highest speech-pitch naming score. Whilst AC also obtained a lower score on the word than complex and pure tone conditions, his score on the word condition was nevertheless strikingly superior to those of controls. We will outline factors that we believe explains AC's unusual ability.

For typically developing infants, social stimuli are extremely salient. In the auditory domain, a powerful orientation to process speech is observed and this has implications for changes in selective attentional mechanisms (Miyawaki et al., 1975) and early developing brain specialisation (for review see: Zhang $\&$ Wang, 2007). Autism is characterised by deficits in socialisation and communication and this is manifested in an early and dramatically reduced orientation to social stimuli, including speech. Recently, Kuhl, Coffey-Corina, Padden, and Dawson (2005) showed that infants with autism who did not ori- ent to child-directed speech had failed to develop specialised speech processing mechanisms observed in typically developing infants. However, discrimination of other types auditory information were not tested and it is unclear whether alternative auditory specialisations, relating to environmental inputs, were in evidence.

The current findings show that healthy individuals with AP can, when necessary, identify fundamental frequencies in speech. However, as language is most informative at semantic and pragmatic levels and absolute pitches in speech possess little or no functional value, a failure to develop finely honed speechpitch naming is unsurprising. Neurological studies have shown that whilst processing of musical and environmental stimuli do not appear to differentiate autism and typical development, patterns of activation in response to speech and vocal sounds are highly atypical in autism (e.g. Čeponienè et al., 2003; Gervais et al., 2004). Gervais et al. have suggested that autism may be characterised by a speech-specific attentional deficit and increased attention to non-speech information. AC possesses exceptionally accurate pitch identification across auditory domains and we hypothesise that AC's early "neglect" of speech and his exposure to music may have contributed to this.

We present data showing extraordinarily accurate pitch naming, spanning both musical and language domains in an able man with autism. Whilst AC is now an articulate multilingual adult, he showed an early pre-occupation with naming pitches and his language acquisition was delayed and atypical. We, therefore, hypothesise that his reduced preferential attention to and processing of language, and increased attention to music, early in life contributed to his exceptional auditory discriminative abilities.

\section{Acknowledgements}

We thank AC and his family, and all our control participants for their support for our study. The work of the first author is supported by EU Grant (12984) Stages in the Evolution and Development of Sign Use (SEDSU).

\section{References}

American Psychiatric Association (1994). Diagnostic and statistical manual for mental disorders (4th ed.). Washington, DC: APA. 
Athos, E. A., Levinson, B., Kistler, A., Zemansky, J., Bostrom, A., Freimer, N., et al. (2007). Dichotomy and perceptual distortions in absolute pitch ability. Proceedings of the National Academy of Sciences of the United States of America, 104(37), 14795-14800.

Baharloo, S., Service, S. K., Risch, N., Gitschier, J., \& Freimer, N. B. (2000). Familial aggregation of absolute pitch. American Journal of Human Genetics, 67(3), 755-758.

Bent, T., Bradlow, A. R., \& Wright, B. A. (2006). The influence of linguistic experience on pitch perception in speech and non-speech sounds. Journal of Experimental Psychology: Human Perception and Performance, 32(1), 97-103.

Bonnel, A., Mottron, L., Peretz, I., Trudel, M., Gallun, E., \& Bonnel, A. M. (2003). Enhanced pitch sensitivity in individuals with autism: A signal detection analysis. Journal of Cognitive Neuroscience, 15, 226-235.

Čeponienè, R., Lepistö, T., Shestakova, A., Vanhala, R., Alku, P., Näätänen, R., et al. (2003). Speech-sound selective auditory impairment in children with autism: They can perceive but not attend. Proceedings of the National Academy of Sciences, 100, 5567-5572.

Gervais, H., Belin, P., Boddaert, N., Leboyer, M., Coez, A., Sfaello, I., et al. (2004). Abnormal cortical voice processing in autism. Nature Neuroscience, 7, 801-802.

Dunn, L. M. (1965). Expanded manual: Peabody picture vocabulary test. Minneapolis: American Guidance Service.

Gillberg, C., \& Coleman, M. (2000). The biology of the autistic syndromes (3rd ed.). London: Mac Keith Press.

Gregersen, P., Kowalsky, E., Kohn, N., \& Marvin, E. (2000). Early childhood music education and predisposition to absolute pitch: Teasing apart genes and environment. American Journal of Medical Genetics, 98, 280-282.

Heaton, P. (2003). Pitch memory, labelling and disembedding in autism. Journal of Child Psychology and Psychiatry, 44, 1-9.

Heaton, P. (2005). Interval and contour processing in autism. Journal of Autism and Developmental Disorders, 35(6), 787-793.

Heaton, P., \& Wallace, G. (2004). Annotation: The savant syndrome. Journal of Child Psychology and Psychiatry, 45(5), 899-911.

Järvinen-Pasley, A. M., Pasley, J., \& Heaton, P. (2008). Is the linguistic content of speech less salient than its perceptual features? Journal of Autism and Developmental Disorders, 38, 239-248.
Klinger, L., Dawson, G., \& Renner, P. (2002). Autistic disorder. In E. Masn \& R. Barkley (Eds.), Child pyschopathology (2nd ed., pp. 409-454). New York: Guildford Press.

Kuhl, P. K., Coffey-Corina, S., Padden, D., \& Dawson, G. (2005). Links between social and linguistic processing of speech in preschool children with autism: Behavioral and electrophysiological measures. Developmental Science, 8 , F9-F20.

Miyawaki, K., Strange, W., Verbrugge, R., Liberman, A., Jenkins, J., \& Fugimura, O. (1975). An effect of linguistic experience: The discrimination of [r] and [1] by native speakers of Japanese and English. Perception and Psychophysics, 18, 331-340.

Miyazaki, K. (1989). Absolute pitch identification: Effects of timbre and pitch region. Music Perception, 7, 1-14.

Mottron, L., Peretz, I., Belleville, S., \& Touleau, N. (1999). Absolute pitch in autism: A case study. Neurocase, 5, 485-501.

Neubäcker, P., \& Gehle, C. (2003). Melodyne Cre8, version 2.0. Munich: Celemony Software GmbH.

Raven, J., Raven, J. C., \& Court, J. H. (1998). Raven manual: Section 3. Standard progressive matrices. Oxford, England: Oxford Psychologists Press.

Schlaug, G., Jaencke, L., Huang, Y., \& Steinmetz, H. (1995). In vivo evidence of structural brain asymmetry in musicians. Science, 267, 699-701.

Smith, N., \& Tsimpli, I. M. (1995). The mind of a savant. Blackell.

Wong, P. C. M., Skoe, E., Russo, N. M., Dees, T., \& Kraus, N. (2007). Musical experience shapes human brainstem encoding of linguistic pitch patterns. Nature Neuroscience, 10, 420-422.

Young, R., \& Nettlebeck, T. (1995). The abilities of a musical savant and his family. Journal of Autism and Developmental Disorders, 25, 229-245.

Zatorre, R. J. (2003). Absolute pitch: A model for understanding the influence of genes and development on neural and cognitive function. Nature Neuroscience, 6(7), 692-695.

Zatorre, R. G., \& Belin, P. (2001). Spectral and temporal processing in human auditory cortex. Cerebral Cortex, 11(10), 946-953.

Zhang, Y., \& Wang, Y. (2007). Neural plasticity in speech acquisition and learning. Bilingualism: Language and Cognition, 10, 147-160. 